\title{
High Blood Pressure and Pregnancy in a Hospital Environment in Lomé: Prognostic and Clinical Epidemiological Aspects
}

\author{
Abago Balaka1,2*, Toyi Tchamdja1,3, Kodjo Agbeko Djagadou1,2, Akila Bassowa ${ }^{2,4}$, \\ Komi Dzidzonu Némi1,2, Lihanimpo Djalogue ${ }^{1,3}$, Komi Edem Mossi1, Abou-Bakari Tchala1, \\ Mohaman Awalou Djibril1,2 \\ ${ }^{1}$ Internal Medicine Unit, Lomé, Togo \\ ${ }^{2}$ Health Science Faculty, University of Lomé, Lomé, Togo \\ ${ }^{3}$ Health Science Faculty, University of Kara, Kara, Togo \\ ${ }^{4}$ Gynecology and Obstetrics Unit, Lomé, Togo \\ Email: ^francisabago@gmail.com
}

How to cite this paper: Balaka, A. Tchamdja, T., Djagadou, K.A., Bassowa, A., Némi, K.D., Djalogue, L., Mossi, K.E., Tchala, A.-B. and Djibril, M.A. (2020) High Blood Pressure and Pregnancy in a Hospital Environment in Lomé: Prognostic and Clinical Epidemiological Aspects. Open Journal of Internal Medicine, 10, 96-101.

https://doi.org/10.4236/ojim.2020.101010

Received: December 7, 2019

Accepted: March 27, 2020

Published: March 30, 2020

Copyright ( 2020 by author(s) and Scientific Research Publishing Inc. This work is licensed under the Creative Commons Attribution International License (CC BY 4.0).

http://creativecommons.org/licenses/by/4.0/ (c) (i) Open Access

\begin{abstract}
Objectives: Study the prognostic, clinical and epidemiological profile of high blood pressure and pregnancy association at the Sylvanus Olympio Teaching Hospital (CHU Sylvanus Olympio) of Lomé. Patients and Method: It is about a retrospective study that is carried out at the gynecology-obstetrics unit from January to December 2016. Pregnant women with High Blood Pressure after delivery were concerned. Results: In total, 767 pregnant women with High Blood Pressure out of 12107 were taken. The frequency of HBP-pregnancy association was $6.33 \%$. The 21 to 30 bracket age was the most represented (53.71\%). The most common risk factor was the overweight or over-obseness (41.98\%). Other risk factors were the first delivery and maternal age superior to 30 years old. Common clinical cases described in the study are the same as a predominance of preeclampsia. Caesarean has been the common method of delivering with foetal complications of prematurity type, neonatal suffering and hypotrophy. Conclusion: HBP-pregnancy association is a public health concern with serious foetal maternal complications. The prevention of this association is of great importance.
\end{abstract}

Keywords

HTA-Pregnancy, Complication, Prognostic, Lomé (Togo)

\section{Introduction}

Pregnancy, considered as a physiological phenomenon, involves sometimes the 
vital prognostic of the mother and or the new-born when it is especially associated with some pathologies. That is the case of High blood pressure (HBP) [1]. High blood pressure (hypertension) is observed during pregnancy with a prevalence of $5 \%$ to $15 \%$. As for eclampsia preceded by pre-eclampsia, its incidence is estimated between 1/2000 pregnancies [1]. This pathology constitutes one of the first causes of maternal-fetal morbidity and mortality in Africa which can be avoided with a responsibility in $30 \%$ of maternal deaths and $20 \%$ of fetal and neonatal mortality [2].

Pregnancy High Blood pressure association is a real problem of public health care in the world with a very variable prevalence according to the studied populations [3] [4] [5] [6]. Complications of this association are extremely serious and dominated in the mother by preeclampsia and in foetal by hypotrophy and prematurity necessitating an early medical care and multidisciplinary in tight collaboration among obstetrician, cardiologist, resuscitator and neonatology [3] [4] [5]. This association in sub-Saharan countries in general and particularly in Togo is not deeply described. We initiated this study that aimed at the study of the profile of this association in a gynecology-obstetrics unit in Lomé.

\section{Patients and Methods}

It is a retrospective study that took place in the gynecology-obstetrics unit at Sylvanus Olympio Teaching Hospital of Lomé. It covered a period of twelve months from January to December 2016. Pregnant women with High Blood Pressure after delivery were concerned. High Blood pressure diagnostics were considered on the basis of systolic High Blood pressure superior or equal to 140 $\mathrm{mmHg}$ and/ or a diastolic HBP superior or equal to $90 \mathrm{mmHg}$ at least two times taken while in rest at left lateral decubicus position or while seated. Studied parameters were the epideomological data (age, socio-professional status, antecedent, High Blood Pressure risk factor, clinical data (mass corporal index calculated from the immediat post-partum weight and the hight, blood pressure figures, oedema), proteinuria. Maternal foetal complications and delivery modalities were also studied. Date collection sheet was the tool used so as to have all its information. We used the software SPSS version 20.0 to analyse the data

\section{Results}

\subsection{Epidemiological Aspects}

Over 12107 patients having delivered, 767 have HBP, that is a frequency of $6.33 \%$.

The group age of 21 to 30 was the most common in $53.71 \%$ (Table 1 ).

\subsection{Medical and Gynecology-Obstetrics Histories}

If $53.6 \%(\mathrm{~N}=411)$ of patients have delivered twice, on the other hand, $16.3 \%(\mathrm{~N}$ $=125)$ delivered more than 4 times. Also, $78 \%(\mathrm{~N}=598)$ of patients were primiparous, and $2.9 \%(\mathrm{~N}=22)$ in a parity superior to 5 . 
71 patients (9.25\%) have high blood pressure (hypertensive) known before pregnancy.

\subsection{Clinical Aspects}

Patients' body index mass calculation made it possible to note that $41.98 \%$ among them were overweight/obeseness. Also, regarding high blood pressure, $85 \%$ of patients were at stage II and III according to the classification of the WHO. Finally, 76.79\% (589 patients) had oedemas at lower limb and proteinuria was tested positive with 726 patients $(94.65 \%)$. The most common clinical form has been pre-eclampsia (86.70\%) (Table 2).

\subsection{Complications Forms}

The major maternal complication was the preeclampsia (86.70\%). La prematurity was the most frequent foetal complication (27.77\%) (Table 3 ).

One must remark that $54.62 \%(\mathrm{~N}=419)$ of patients had delivered by caesarean.

Table 1. Distribution of patients en according to the age (in year).

\begin{tabular}{ccc}
\hline & Number & Percentage (\%) \\
\hline [Inferior to 21] & 79 & 10.29 \\
{$[21$ à 31] } & 412 & 53.71 \\
{$[31$ à 41] } & 259 & 33.76 \\
Superior to 40 & 17 & 02.21 \\
Total & 767 & 100 \\
\hline
\end{tabular}

Table 2. Distribution of patients by clinical form.

\begin{tabular}{ccc}
\hline & Number & Percentage (\%) \\
\hline Chronic (HTA-HBP) & 10 & 1.30 \\
Gravid (HTA-HBP) & 31 & 4.04 \\
Pre-eclampsia & 665 & 86.70 \\
Over added Pre-eclampsia & 61 & 7.95 \\
Total & 767 & 100 \\
\hline
\end{tabular}

Table 3. Patients distribution according to fotal complications.

\begin{tabular}{ccc}
\hline & Number & Percentage (\%) \\
\hline Prematurity & 213 & 27.77 \\
Neonatal suffering & 56 & 7.30 \\
Dead & 5 & 0.65 \\
Hypotrophy & 26 & 3.38 \\
NO complication & 467 & 60.88 \\
Total & 767 & 100 \\
\hline
\end{tabular}




\section{Discussion}

This study tells us that the frequency of HBP-pregnancy association was $6.33 \%$. The 21 to 30 bracket age (53.71\%) was the most represented. The most common risk factor was the overweight or over-obseness (41.98\%). Common clinical cases described in the study are the same as a predominance of preeclampsia. Caesarean has been the common method of delivering with foetal complications of prematurity type, neonatal suffering and hypotrophy. The present study has limitations due to its retrospective nature. There is thus a bias in recruitment and selection. However, the size of the sample, the site where the study was carried out and the inclusion criteria gives the study strength and replicability.

We have noted in our study a frequency of hypertension-pregnancy association at $6.33 \%$. This frequency is estimated between $5 \%$ and $10 \%$ in the USA [4], $10 \%$ to $15 \%$ in France [5]. In sub-Saharan Africa, it is estimated at $17.05 \%$ in Guinea Conakry [6], 8.9\% in Niger [7] and 7.65\% in Benin [8]. The frequency of High Blood Pressure Pregnancy is therefore variously appreciated in the study. Even if our frequency is close to that of some authors [4] [7] [8], we think that it is certainly underestimated since our work did not only take into account the ongoing of the unit in delivery. In our study, the age bracket of 21 to 30 was the most represented (53.71\%) followed by that of 31 to 40 years; unlike Baragou's study [9] who noted that the age group from 30 to 39 is the majority (50\%). However, our result is similar to that of some authors in the sub-region [6] [7] [8]. Overweight/obesity was the first risk factor found in our series $(41.98 \%)$ confirming data of the study [5]-[10]. HBP was grade 2 in the majority of cases in our study (85\%) as in [4]-[9] series and oedema of the lower limbs was objectified in $76.79 \%$ of cases. It should be noted that oedema of the lower extremities is frequent, especially in late pregnancy, but they are pathological only when they are associated with blood pressure or proteinuria different from an episode of urinary infection [11] [12]. Thus preeclampsia was the major maternal complication in our series. This preponderance of preeclampsia is also reported in a Guinean series [6] and in another Togolese series [9].

Preeclampsia is an obstetric emergency because it involves the maternal-foetal vital prognosis [13]. Health expansion and multidisciplinary care (obstetrician, pediatrician, and intensive care) made it possible to reduce maternal morbidity and mortality, especially in developed countries [13]. In developing countries where health centers are confronted with a shortage of technical facilities, prevention is compulsory by mainly affecting on preventable risk factors such as: obesity, sedentary lifestyle, diabetes, dyslipidemia and diabetes.

Prematurity (27.77\%), neonatal distress (7.30\%), hypotrophy (3.38\%) and fetal death $(0.65)$ were the fetal complications in our series. In fact, prematurity often iatrogenic and secondary hypotrophy at placental insufficiency are the two complications extremely common with a foetal and neonatal mortality rate ranging from $12.5 \%$ to $35 \%$ [6] [7] [14] [15] [16]. 


\section{Conclusion}

HBP-pregnancy association represents a public health problem with dreadful complications. We must more lay emphasis on the avoidable prevention of risk factors and educating pregnant women.

\section{Conflicts of Interest}

The authors declare no conflicts of interest regarding the publication of this paper.

\section{References}

[1] WHO (2013) Hypertension: The Basic Facts. A Global Brief on Hypertension. WHO, Geneva, 17-21.

[2] Jadhav, V. and Waydande, S. (2016) A Study of Prevalence and Clinical Profile of the Patients Having Hypertensive Disorders of Pregnancy. The International Journal of Resent trends in Science \& Technology, 21, 73-76.

[3] American College of Obstetricians and Gynecologists (2002) Diagnosis and Management of Preeclampsia and Eclampsia ACOG Practice. Obstetrics and Gynecology, 99, 159-167. https://doi.org/10.1097/00006250-200201000-00028

[4] (2000) Report of the National High Blood Pressure Education Program Working Group on High Blood Pressure in Pregnancy. American Journal of Obstetrics \& Gynecology, 183, S1-S22. https://doi.org/10.1067/mob.2000.107928

[5] Sentilhes, L., Gillard, P., Biquard, F. and Deschamps, P. (2008) Hypertension et grossesse. In: Obstétrique pour le praticien, 5th Edition, Masson, Paris, 161-171.

[6] Bah, A.O., Diallo, M.H., Diallo, A.A.S., Keita, N. and Diallo, M.S. (2000) Hypertension artérielle et grossesse: Aspects épidémiologiques et facteurs de risques. Médecine d Afrique Noire, 47, 422-425.

[7] Touré, I.A., Brah, F. and Prual, A. (1997) Hypertension artérielle et grossesse au Niger Etude cas/témoins à propos de 70 cas. Médecine d Afrique Noire, 44, 205-208.

[8] Attolou, V., Takpara, I. and Jetal, A. (1998) Les différents types d'HTA chez les femmes enceintes béninoises admise au CNHU de Cotonou. Cahiers détudes et de recherches Francophones/ Santé, 8, 353-356.

[9] Baragou, S., Goeh-Akue, E., Pio, M., Affassinou, Y.M. and Atta, B. (2014) Hypertension artérielle et grossesse à Lomé: Aspect épidémiologique diagnostic et facteurs de risque. Annales de cardiologie et d Angéiologie, 3, 145-150. https://doi.org/10.1016/j.ancard.2014.05.006

[10] Krzesinski, J.M. (1999) HTA et grossesse. Revue medicale de Liege, 54, 415-423.

[11] Mounier-Vehier, C., Equine, O., Valat-Rigot, A.S., et al. (1999) Syndromes hypertensifs de la femme enceinte: Physiologie, définition et complications évolutives materno-foetales. La Presse médicale, 28, 880-885.

[12] Couture, G. and Milot, A. (2002) Hypertension artérielle et grossesse. In: Société Québécoise d hypertension artérielle, Guide thérapeutique, 2nd édition, 97-120.

[13] (2000) Conférence d'experts. Réanimation des formes graves de préeclampsie (texte cours). Société francaise d'anesthési-réanimation (SFAR). Elsevier, Paris, 260 p.

[14] Ducarme, G., Heernberger, S., Pharisien, I. and Carbillon, L. (2009) Eclampsie: Etude rétrospective de 16 cas. Gynécologie Obstétrique \& Fertilité, 37, 11-17.

https://doi.org/10.1016/j.gyobfe.2008.11.011 
[15] Mounier-Vehier, C., Madika, A.L., Boudghène-Stambouli, F., Ledieu, G., Delsart, P. and Tsatsaris, V. (2016) Hypertensions artérielles de la grossesse et devenir maternel. Presse Médicale, 45, 659-666. https://doi.org/10.1016/j.lpm.2016.05.017

[16] Say, L., Chou, D., Gemmill, A., Tunçalp, Ö., Moller, A.-B., Daniels, J., et al. (2014) Global Causes of Maternal Death: A WHO Systematic Analysis. The Lancet Global Health, 2, 323-333. https://doi.org/10.1016/S2214-109X(14)70227-X 